\title{
ARTI PENTING TINGKAT KEPUASAN PARA PELANGGAN DAN PEMANFAATAN ULASAN DARING
}

Dewanta Fachrureza,

Program studi perhotelan, Akademi Pariwisata Bunda Mulia, Jakarta, dfacrureza@,bundamulia.ac.id

\begin{abstract}
ABSTRAK
Penelitian ini berangkat dari rasa keingintahuan peneliti untuk mencari tahu sejauh mana pemanfaatan ulasan pelanggan daring pada hotel Ritz Carlton, dikarenakan manajemen hotel sangat menanggapi dengan baik bahkan bisa dikatakan luar biasa dalam menanggapi ulasan pelanggan daring terutama dari TripAdvisor. Tujuan dari penelitianini adalah untuk mengembangkan dan memahami sejauh mana pemanfaatan ulasan pelangganulasan daring dari TripAdvisor ke departemen Departmen kantor depan di Hotel Ritz Carlton Jakarta. Simpulan dari Penelitian ini adalah penting bagi hotel untuk mempertahankan dan meningkatkan tingkat kepuasan pelanggan untuk meningkatkan kualitas layanan hotel. Peneliti juga memberikan beberapa saran yang menyatakan bahwa harus ada posisi pekerjaan yang bertanggung jawab untuk memastikan bahwa semua ulasan daring akan dijawab dan dievaluasi. Selain itu, hotel harus mengundang lebih banyak tamu untuk memberikan komentar mereka di TripAdvisor.

Kata Kunci: Pelanggan, Kepuasan Pelanggan, Ulasan daring, Departmen kantor depan
\end{abstract}

\section{ABSTRACT}

This research departs from the curiosity of researchers to find out the extent to which online customer reviews are used at the Ritz Carlton hotel, because hotel management responds well even to the extraordinary in responding to online customer reviews, especially from TripAdvisor. The purpose of this study is to develop and understand the extent to which online review customer reviews are used from TripAdvisor to the department of the front office at the Ritz Carlton Hotel Jakarta. Conclusions from this study are important for hotels to maintain and improve the level of customer satisfaction to improve the quality of hotel services. The researcher also gave several suggestions which stated that there must be a position of work that is responsible for ensuring that all online reviews will be answered and evaluated. In addition, the hotel must invite more guests to comment on TripAdvisor.

Keywords: Customer, Customer Satisfaction, Online Review, Front Office Department 


\section{National Conference of Creative Industry: \\ Sustainable Tourism Industry for Economic Development}

Universitas Bunda Mulia, Jakarta, 5-6 September 2018

ISSN No: 2622-7436

\section{PENDAHULUAN}

Mengenai ulasan daring tamu dari TripAdvisor, Hotel Ritz Carlton Jakarta menggunakan salah satu alat berkualitas untuk mempertahankan kepuasan pelanggan yang merupakan jejaring sosial seperti TripAdvisor. Selama pengamatan peneliti di hotel, manajemen hotel menunjukkan perhatian terkait ulasan daring tamu. Perhatian khusus itu dapat dilihat seperti berikut:

1. Staf GRO dari Ritz Carlton selalu memeriksa peringkat dari situsulasan daring dan selalu membagikannya pada setiap briefing pagi ataupun sore..

2. Staf GRO dari Ritz Carlton selalu melakukan 'email blast' kepada semua tamu yang check-out, sehingga mereka dapat memberikan ulasan mereka tentang pengalamanmereka ketika tinggal di hotel Ritz Carlton di TripAdvisor.

3. Jika ada komentar bagus atau komentar buruk dari komentar tamu daring di situs seperti TripAdvisor, setiap staf yang melihatnya harus membagikannya info tersebut kepada yang lain. Jika ada komentar bagus, pihak manajemen akan mengirimkan surat apresiasi melalui email, atau souvenir untuk tamu. Jika ada komentar buruk, kami mengirimkan permintaan maaf secara personal dan solusi untuk menangani keluhan.

Selama enam bulan penelitimelakukan observasi, peneliti telah mengamati bahwa ulasan daring tamu di TripAdvisor, (salah satu situs paling populer di dunia untuk akomodasi perjalanan), digunakan sebagai umpan balik untuk hotel. Ulasan daring memberikan publisitas dan transparansi secara daring

\section{Urgensi Penelitian}

Melihat fenomena yang terjadi dimana pihak hotel terutama departmen kantor depan selalu menanggapi serius dan menjadikan ulasan daring di TripAdvisor sebagai acuan utama dalam mengulas performa departmen kantor depan, peneliti merasa harus melakukan penelitian seberapa pentingnya ulasan daring bagi pihak departmen kantor depan hotel Ritz Carlton Jakarta. Agar nantinya dapat diaplikasikan di unit property lainya terutama sister group Ritz Carlton.

Berdasarkan identifikasi masalah, peneliti melakukan penelitian ini dengan judul "ARTI PENTING TINGKAT KEPUASAN PARA PELANGGAN DAN PEMANFAATAN ULASAN DARING"

Dari identifikasi masalah di atas, peneliti membuat batasan untuk penelitianyaitu menganalisis sejauh mana pemanfaatn ulasan pelanggan oleh pihak hotel Peneliti merumuskan masalah menjadi satu pertanyaan:

1. Sejauh mana pemanfaatan ulasan pelanggan sebagai cerminan kepuasan pelanggan? 


\section{TINJUAN PUSTAKA}

Dalam konteks pemahaman hotel, departmen kantor depan adalah departemen yang terletak di depan hotel. Tidak jauh dari pintu depan hotel atau lobi. Daerah ini adalah tempat tersibuk di hotel. Dengan lokasi di depan, itu juga rumah departemen yang paling mudah dicari dan dilihat oleh tamu. (Bagyono, 2006: 21). Grigoroudis \& Siskos (2010, p. 8) menyatakan bahwa pelanggan adalah orang yang membeli produk atau layanan yang ditawarkan oleh organisasi bisnis. Kepuasan, di sisi lain, dipandang dalam bentuk kejadian tunggal yang mengarah ke hasil konsumsi (kesan kolektif dari peristiwa-peristiwa ini) dan akhirnya ke seluruh penilaian pengalaman.

Berdasarkan Hill, et al (2003, p.7), kepuasan pelanggan adalah ukuran bagaimana kinerja total produk organisasi Anda dalam kaitannya dengan serangkaian persyaratan pelanggan. Kepuasan pelanggan terkait dengan seberapa baik pelanggan dapat memprediksi tingkat kinerja di mana produk atau layanan akan memuaskan mereka (Grigoroudis \& Siskos 2010, p. 9).

Efek dari kepuasan pelangan ditunjukan dari gambar dibawah ini

\section{THE EFFECT OF CUSTOMER SATISFACTION TO CUSTOMER}

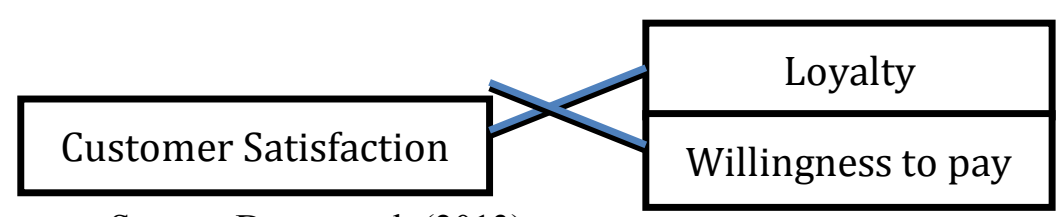

Source: Deng, et al. (2013)

Tingkat kepuasan pelanggan yang tinggi harus mengarah pada peningkatan profitabilitas Pembelian berulang karena bertingkat Permintaan. Ini akan berubah menjadi kinerja keuangan atau penjualan hotel yang lebih baik (Enz 2010, p 371; Sun \& Kim 2013).

\section{THE EFFECT OF CUSTOMER SATISFACTION FOR HOTEL}

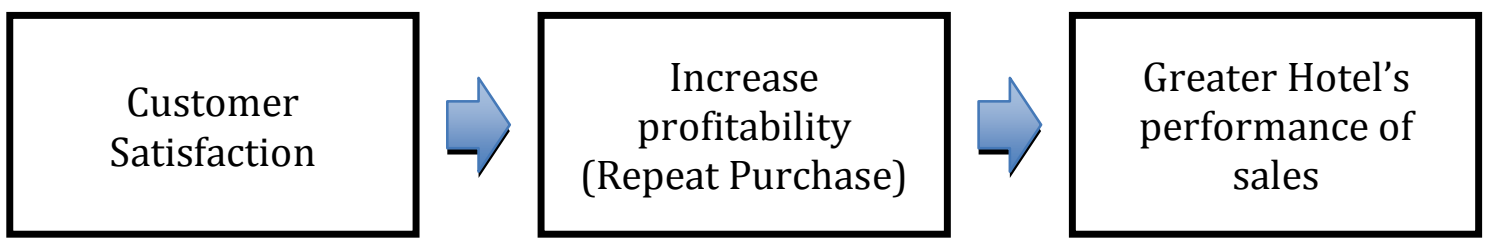

Source: Enz (2010, p.371); Sun \& Kim (2013)

Tingkat kepuasan pelanggan yang tinggi harus mengarah pada peningkatan profitabilitas pembelian berulang karena meningkatnya permintaan. Ini akan berubah menjadi kinerja keuangan atau penjualan hotel yang lebih baik (Enz 2010, p 371; Sun \& Kim 2013).

Berdasarkan Hill, dkk. (2003), tujuan mengukur kepuasan pelanggan untuk mengetahui seberapa puas pelanggan dengan kinerja organisasi adalah pada daftar persyaratan pelanggan yang sama. Dalam mengukur kepuasan pelanggan, berbagai jenis survei dapat digunakan. Ada empat opsi dasar seperti: 


\section{National Conference of Creative Industry: \\ Sustainable Tourism Industry for Economic Development}

Universitas Bunda Mulia, Jakarta, 5-6 September 2018

ISSN No: 2622-7436

\section{Ulasan Pelanggan Daring}

Ulasan pelanggan daring adalah salah satu jenis word of mouth. Hal ini menyediakan informasi produk dan rekomendasi dari perspektif pelanggan. Ulasan daring memberikan industri perhotelan dengan umpan balik dari pelanggan dan mendapatkan banyak info dari hal tersebut. Manajer dapat bekerja dengan peningkatan produk atau layanan, dan masalah yang dialami oleh pengunjung. Ini memungkinkan manajer untuk menganalisis dan meningkatkan kepuasan pelanggan yang dapat menyebabkan keunggulan kompetitif dan reputasi merek yang baik (Goldsmith, et al. 2008).

Pelanggan sering memposting ulasan, rekomendasi, atau pendapat mereka secara daring (misalnya, situs pemesanan pihak ketiga setelah pengalaman mereka di hotel). Ulasan ini bertindak sebagai kata elektronik dari mulut ke mulut dan memainkan peran penting dalam menghasilkan keakraban dan kepercayaan pelanggan (Ye, et al. 2009). Pelanggan memposting ulasan positif, ulasan negatif, atau keduanya daring setelah pengalaman mereka di hotel. Ulasan positif menunjukkan kepuasan pelanggan sementara ulasan negatif menunjukkan ketidakpuasan pelanggan. Dibandingkan dengan penilaian pelanggan, ulasan dalam kata mencerminkan kepuasan atau ketidakpuasan pelanggan dengan cara yang lebih rinci karena ulasannya lebih informatif. Mengidentifikasi jenis dan pentingnya determinan kepuasan pelanggan dan ketidakpuasan dalam ulasan pelanggan adalah langkah untuk menghasilkan tuntutan yang lebih besar.

\section{METODE PENELITIAN}

Metodologi penelitian adalah cara sistematis untuk memecahkan masalah. metode penelitian yang digunakan adalah grounded theory Yang artinya adalah metode penelitian kualitatif yang menggunakan sejumlah prosedur sistematis guna mengembangkan teori dari lapangan. (Glaser dan Strauss, The Discovery of Grounded Theory, 1967)

Metode Grounded Theory bersifat konseptual atau teori sebagai hasil pemikiran induktif dari data yang dihasilkan dalam penelitian mengenai suatu fenomena. Atau suatu teori yang dibangun dari data suatu fenomena dan dianalisis secara induktif, bukan hasil pengujian teori yang telah ada.

Ciri Penelitian Grounded Theory adalah:

- Grounded theory dibangun dari data tentang suatu fenomena

- Penyusunan teori tersebut dilakukan dengan analisis data secara induktif

- Agar penyusunan teori menghasilkan teori yang benar disamping harus dipenuhi 4 (empat) kriteria yaitu: cocok, dipahami, berlaku umum, pengawasan, juga diperlukan dimilikinya kepekaan teoretik (theoretical sensitivity) dari si peneliti.

- Peneliti mempunyai wawasan yang luas

\section{Pengembangan Instrumen}

Responden

Responden dalam penelitian ini adalah para karyawanGRO dan reception yang langsung merasakan dampak pentingnya ulasan daring.

Sumber Data 
Sumber data menggunakan triangulasi sumber data, yang artinya adalah menggali kebenaran informasi tertentu melalui wawancara dan observasi (participant observation) serta dokumen tertulis atau gambar.

\section{Teknik Analisis Data}

Peneliti akan menggunakan Teknik analisis data deskriptif, yaitu merupakan tekhnik analisis yang dipakai untuk menganalisis data dengan mendeskripsikan atau menggambarkan datayang sudah dikumpulkan seadanya tanpa ada maksud membuat generalisasi dari hasil penelitian. Yang termasuk dalam teknik analisis data statistik deskriptif diantaranya seperti penyajian data kedalam bentuk grafik, tabel, presentase distribusi frekwensi, diagram. Peneliti juga akan menggunakan teknik analisis yang digunakan adalah Teknik Penyajian data (data display) yang merupakan salah satu dari teknik analisis data kualitatif. Penyajian data adalah kegiatan ketika sekumpulan informasi disusun, sehingga memberi kemungkinan akan adanya penarikan simpulan. Bentuk penyajian data kualitatif berupa teks naratif (berbentuk catatan lapangan), matriks, grafik, jaringan dan bagan. (Menurut Miles dan Huberman)

\section{HASIL PENELITIAN DAN PEMBAHASAN}

Pada bagian ini, peneliti menyajikan analisis data dengan membuat beberapa perhitungan rata-rata dari ulasan daring melalui TripAdvisor, dan juga menyajikan hasil wawancara dilakukan dengan beberapa staf departmen kantor depan di Ritz Carlton Jakarta. Total responden 8 orang. Karakteristik responden ditunjukkan di bawah ini.

\section{TabelKarakterisrikResponden}

\begin{tabular}{|c|l|c|c|c|}
\hline No & \multicolumn{1}{|c|}{ Name } & Posisi & Umur & Lama kerja \\
\hline 1 & Fahrudin & GRO & 28 & 6 bulan \\
\hline 2 & Airin & GRO & 26 & 1 tahun \\
\hline 3 & Ahmad Khoirudin & Reception & 29 & 10 bulan \\
\hline 4 & Annisa Permata & Reception & 32 & 2 Tahun \\
\hline 5 & Jessica Wijaya & Reception & 26 & 1 bulan \\
\hline 6 & Prisil & GRO & 26 & 2 tahun \\
\hline 7 & Maimunah nur & ReceptionSupervisor & 28 & 2tahun \\
\hline 8 & Almiranda Utmi & Reception & 30 & 3tahun \\
& & & & \\
\hline
\end{tabular}

Untuk memperoleh data ini, peneliti melakukan wawancara. Hasilnya ditunjukkan di bawah ini.

- Pertanyaan 1: Apakah anda merasa ulasan daringpelanggan melaluiTripAdvisor sangat penting untuk diketahui oleh bagian departmen kantor depan?

Hasil: 


\section{GrafikHasil Wawancara}

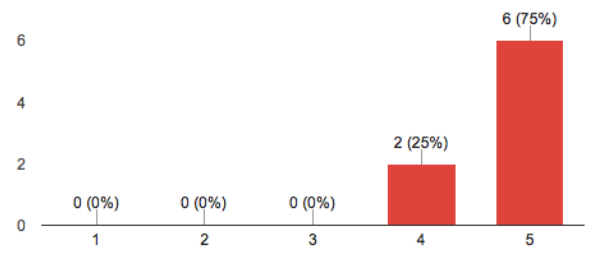

Semua responden mengatakan penting (point 4) dan sangat penting (point 5) bagi departemen Departmen kantor depan untuk mengetahui tingkat kepuasan pelanggan melalu ulasan daring. Untuk alasan mengapa sangat penting bagi pihak departmen kantor depan akan di jelaskan di pertanyaan wawancara nomer 3.

- Pertanyaan 2:Seberapa penting tingkat kepuasan tamu pada situs ulasan daring harus diketahui oleh departemen Departmen kantor depan?

Hasil:

\section{GrafikHasil Wawancara}

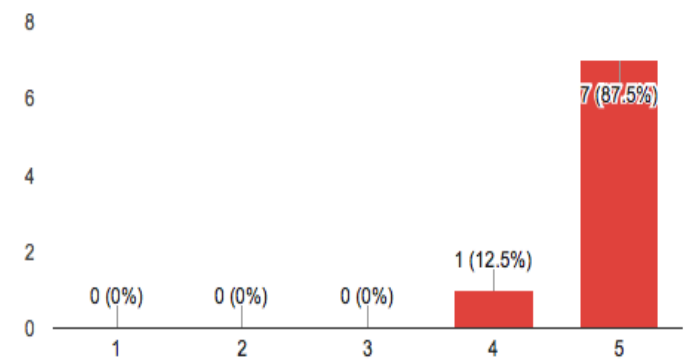

Tingkat kepentingan kepuasan tamu atau rating hotel di situs daring harus diketahui oleh Departmen kantor depan Department mendapat point 5 dari 5. Itu artinya sangat penting. Hasil wawancara ini menguatkan hasil wawancara pada pertanyaan nomer 1. Yang mengatakan bahwa sangat penting bagi departemen Departmen kantor depan untuk mengetahui tingkat kepuasan pelanggan melalu ulasan daring.

Wawancara berikut akan menjelaskan alasan secara verbal dari sudut pandang para karyawandepartmen kantor depan mengapa tingkat kepuasan tamu atau peringkat hotel di situs daring harus diketahui oleh departemen Departmen kantor depan

- Pertanyaan 3:Mengapa tingkat kepuasan tamu di situs daring harus diketahui Hasil: oleh departemen Departmen kantor depan? 


\section{Hasil Wawancara Tentang Mengapa Tingkat Kepuasan Tamu Pada Situs Daring Harus Diketahui Departemen Depan Departmen kantor depan}

\begin{tabular}{|l|l|}
\hline \multicolumn{2}{|c|}{$\begin{array}{c}\text { Mengapa tingkat kepuasan tamu atau peringkat hotel di situs daring } \\
\text { harus diketahui oleh departemen Departmen kantor depan? }\end{array}$} \\
\hline Responden 1: & $\begin{array}{l}\text { Agar dapat meningkatkan kualitas pelayanan pada } \\
\text { hotel. }\end{array}$ \\
\hline Responden 2: & $\begin{array}{l}\text { Kantuk mengetahui kepuasan pelanggan } \\
\text { hotel, ketika ada komentar buruk tentang departmen } \\
\text { kantor depanartinya pelayanan harus segera } \\
\text { diperbaiki untuk memperbaiki komentar buruk yang } \\
\text { tadi disebutkan }\end{array}$ \\
\hline Responden 3: & $\begin{array}{l}\text { Penting untuk meningkatkan layanan hotel kami. } \\
\text { Jika ada komentar negatif atau keluhan yang perlu } \\
\text { diperbaiki maka sebagai referensi kita untuk } \\
\text { meningkatkan kualitas pelayanan. }\end{array}$ \\
\hline Responden 4: & $\begin{array}{l}\text { Karena Departmen kantor depan sebagai kesan } \\
\text { pertama dari hotel dan menampung keluhan tamu } \\
\text { dapat membantu untuk mencegah keluhan serupa } \\
\text { terjadi lagi }\end{array}$ \\
\hline Responden 5: & $\begin{array}{l}\text { menjadi panduan kami selama bekerja. Bahkan } \\
\text { dalam bisnis, kita dapat meningkatkan kepuasan } \\
\text { pelanggan dan mendapatkan manfaat dari ulasan } \\
\text { daring tersebut }\end{array}$ \\
\hline Responden 6: & $\begin{array}{l}\text { Kepuasan pelangan adalah cerminan dari apa yang } \\
\text { hotel berikan kepada pelangan sebagai pilihan yang } \\
\text { mereka pilih untuk menginap. }\end{array}$ \\
\hline Rntuk meningkatkan pelayanan lebih baik lagi. \\
\hline Responden 7:
\end{tabular}

Dari wawancara di atas, karyawan berpendapat berbeda-beda namun semua bermuara kepada kepuasan pelanggan dan citra hotel di mata tamu. peneliti dapat menyimpulkan bahwa tingkat kepuasan tamu atau rating hotel di situs daring harus diketahui oleh departemen Departmen kantor depan karena dapat digunakan untuk meningkatkan kualitas layanan hotel dan menjaga kepuasan pelanggan. Pertanyaan berikut akan menguatkan pernyataan peneliti tentang seberapa penting mempertahankan atau meningkatkan tingkat kepuasan tamu yang diisi oleh tamu di situs ulasan daring.

- Pertanyaan 4:Menurut anda, seberapa penting untuk mempertahankan dan meningkatkan tingkat kepuasan tamu yang diisi oleh tamu di situsulasan daring?

Hasil: 


\section{Grafik Dari Hasil Wawancara}

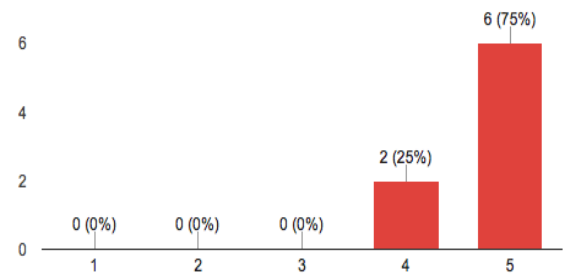

Kebanyakan dari responden mengatakan bahwa sangat penting untuk merawat atau meningkatkan tingkat kepuasan tamu yang diisi oleh tamu di situsulasan daring, dan tingkat pentingnya mendapat poin 5 dari 5 . Ini berarti bahwa para staf berpikir sangat penting untuk mempertahankan atau meningkatkan tingkat kepuasan pelanggan. Pada wawancara berikut akan menjelaskan apa saja yang sudah dilakukan oleh pihak FO department untuk mempertahankan atau meningkatkan tingkat dari kepuasan pelanggan di situs ulasan daring

- Pertanyaan 5:Apa saja yang sudah dilakukan oleh departemen Departmen kantor depan untuk mempertahankan dam meningkatkan tingkat dari kepuasan pelanggan di situsulasan daring?

Hasil:

\section{Hasil Wawancara Dari Apa Saja Yang Sudah Dilakukan Oleh Departemen Departmen kantor depan Untuk Mempertahankan Atau Meningkatkan Tingkat Dari Kepuasan Pelanggan Di SitusUlasan daring}

\begin{tabular}{|l|l|}
\hline \multicolumn{2}{|c|}{$\begin{array}{c}\text { Apa Saja Yang Sudah Dilakukan Oleh Departemen Departmen } \\
\text { kantor depan Untuk Mempertahankan Atau Meningkatkan Tingkat } \\
\text { Dari Kepuasan Pelanggan Di SitusUlasan daring }\end{array}$} \\
\hline Responden 1: & Not valid answer \\
\hline Responden 2: & Berikan service terbaik \\
\hline Responden 3: & $\begin{array}{l}\text { Mempertahankan dan meningkatkan kinerja dalam } \\
\text { konteks pelayanan dan hospitality kepada pelanggan } \\
\text { atau customer. }\end{array}$ \\
\hline Responden 4: & $\begin{array}{l}\text { Tetap konsisten dalam memberikan service terbaik } \\
\text { dan tetap bersahabat juga mengerti kepada keinginan } \\
\text { tamu. }\end{array}$ \\
\hline Responden 5: & $\begin{array}{l}\text { Jaga kepercayaan tamu dan menangani keluhan tamu } \\
\text { dengan cepat. Selalu jaga kontak dan terus } \\
\text { berhubungan dengan tamu dengan selalu mengetahui } \\
\text { apa yang tamu perlukan. }\end{array}$ \\
\hline Responden 6: & $\begin{array}{l}\text { Lakukan pelayanan maksimal dalam menangani } \\
\text { keluhan tamu. Tetap berusaha untuk terus menutup }\end{array}$ \\
\hline
\end{tabular}




\begin{tabular}{|l|l|}
\hline & $\begin{array}{l}\text { kekurangan yang harus ditingkatan dan juga } \\
\text { mengerti kemauan pasar lebih baik lagi. }\end{array}$ \\
\hline Responden 7: & $\begin{array}{l}\text { Berikan service yang baik dan keramah-tamahan } \\
\text { kepada tamu. Juga selalu menjadi pelayan yang siap } \\
\text { membantu tamu dalam segala kondisi. }\end{array}$ \\
\hline Responden 8: & $\begin{array}{l}\text { Selesaikan keluahn tamu sebelum tamu } \\
\text { meninggalkan hotel dan pastikan tamu merasa puas } \\
\text { dan bahagia menginap di hotel kita. }\end{array}$ \\
\hline
\end{tabular}

Dari wawancara itu disimpulkan apa yang telah dilakukan oleh departemen Departmen kantor depan untuk mempertahankan atau meningkatkan tingkat kepuasan tamu hotel di situs ulasan daring. Yang telah dilakukan adalah:

- Dengan memberikan layanan yang baik.

- Dengan mempertahankan dan meningkatkan kinerja kerja dalam hal layanan dan keramahan kepada tamu.

- Dengan tetap konsisten dalam memberikan layanan.

- Dengan ramah dan memahami kebutuhan para tamu.

- Dengan menjaga kepercayaan yang diberikan oleh tamu dan menangani keluhan tamu sesegera mungkin.

- Dengan tetap berhubungan dengan mengetahui apa yang dibutuhkan para tamu.

- Dengan melakukan one stop service untuk keluhan tamu.

- Dengan terus memperbaiki kekurangan dan terus memahami apa yang diinginkan pasar.

- Dengan memberikan layanan dan keramahan yang baik kepada tamu, dan juga dengan membantu setiap tamu.

- Dengan menyelesaikan keluhan para tamu sebelum meninggalkan hotel dan dengan memastikan bahwa tamu senang.

Dapat disimpulkan bahwa pihak FO department sudah melakukan banyak hal untuk yang bersifat fundamental untuk kepuasan tamu. Hal ini membuktikan bahwa karyawan FO departemen sangat ingin mempertahankan atau meningkatkan tingkat kepuasan tamu hotel di situs ulasan daring.

Pertanyaan berikut akan menjelaskan lebih dalam lagi sejauh mana sebuah ulasan daring dapat dimanfaatkan oleh pihak FO department.

○ Pertanyaan 6:Sejauh mana ulasan daring dapat dimanfaatkan oleh pihak departemen Departmen kantor depandalam memaksimalkan kepuasan pelanggan?

Hasil: 


\section{National Conference of Creative Industry: \\ Sustainable Tourism Industry for Economic Development}

Universitas Bunda Mulia, Jakarta, 5-6 September 2018

ISSN No: 2622-7436

\section{Sejauh Mana Ulasan Daring Dapat Dimanfaatkan Oleh Pihak Departemen Departmen kantor depan Dalam Memaksimalkan Kepuasan Pelanggan}

\begin{tabular}{|l|l|}
\hline \multicolumn{2}{|c|}{$\begin{array}{c}\text { Sejauh mana ulasan daring dapat dimanfaatkan oleh pihak } \\
\text { departemen Departmen kantor depan dalam memaksimalkan } \\
\text { kepuasan pelanggan }\end{array}$} \\
\hline Responden 1: & $\begin{array}{l}\text { Dinilai sangat bermanfaat, khususnya dalam menilai } \\
\text { kepuasan pelanggan }\end{array}$ \\
\hline Responden 2: & Bermanfaat dalam cerminan kinerja FO \\
\hline Responden 3: & Sebagai laporan paling jujur dari tamu \\
\hline Responden 4: & Sebuah pemicu untuk bekerja lebih baik lagi \\
\hline Responden 5: & Dapat mengetahui penilaian tamu dengan cepat \\
\hline Responden 6: & Sebagai alat atau tool untuk menjaga image hotel \\
\hline Responden 7: & $\begin{array}{l}\text { Alat bantu untuk memberikan lebih baik lagi untuk } \\
\text { tamu }\end{array}$ \\
\hline Responden 8: & Dapat memastikan kepuasan tamu dengan cepat. \\
\hline
\end{tabular}

Dari wawancara di atas, peneliti dapat menyimpulkan bahwa ulasan daring dapat dimanfaatkan oleh pihak departemen Departmen kantor depan dalam banyak hal, tidak saja hanya sebagai cerminan kepuasan pelanggan namun juga bisa berperan dalam banyak hal guna menunjang kinerja pihak FO Departmen.

Setelah melakukan banyak wawancara diatas, peneliti menemukan sebuah simpulan bahwa tingkat kepuasan pelanggan melalui ulasan daring dari TripAdvisor di Ritz Carlton Jakarta sangat penting. Dibuktikan dari hasil observasi peneliti di kolom komentar TripAdvisor, dimana ketika ada komentar buruk, yang menggapi langsung adalah seorang General Manager, ditambahkan lagi fakta berdasarkan wawancara yang dilakukan terbukti bermanfaat dan penting bagi pihak departmen kantor depan dengan berbagai pendapat yang diberikan jika disimpulkan akan mengacu pada sangat penting dan bermanfaatnya ulasan daring tamu. Dan karena hal itu juga pihak departmen kantor depan merasa perlu dipertahankan bahkan ditingkatkan agar kepuasan tamu lebih meningkat lagi.

Mengenai pernyataan ini, peneliti juga mewawancarai Manajer Departmen kantor depan. Beliau mengatakan bahwa ulasan daring adalah salah satu tool atau alat untuk menarik pelanggan dari segmen FIT (Free Individual Traveler) dan tamu restoran. Semakin baik peringkat, semakin baik hotel ini di mata customer dan calon customer dan ini akan membuat semakin banyak tamu datang untuk menginap. Penting bagi hotel untuk menanggapi komentar pada ulasan daring; Ini berarti adanya kekhawatiran yang berkelanjutan dari manajemen hotel tentang komentar buruk di dunia maya, dan itu menunjukkan standar hotel itu sendiri, dan itu menunjukkan bahwa jika hotel tidak memperhatikan ulasan daring, maka hotel akan kurang mampu untuk mengikat tamu-tamu baru terutama tamu FIT. Selain itu, beliau juga menyatakan bahwa manfaat dari perhatian terhadap ulasan daring dari TripAdvisor adalah bahwa kita tahu keburukan dan barang hotel dari respon tamu, dan paradigma setiap kekurangan yang harus diperbaiki, sehingga ide-ide baru yang berkaitan dengan pembaruan atau rencana pemulihan akan muncul. 
Terkadang, di TripAdvisor, ada juga komentar tidak valid dari akun yang tidak dikenal. Tentang hal ini, beliau menyatakan bahwa komentar tidak sah ditanggapi secara positif, karena kita tidak dapat membatasi ruang publik dan siapa pun dapat menyatakan apa pun. Namun, ia juga menyatakan bahwa komentar yang tidak valid harus diperiksa dan dilaporkan ke TripAdvisor jika pihak manajemen dapat menunjukkan bukti bahwa itu tidak benar dan itu tidak pernah terjadi.

\section{KESIMPULAN DAN IMPLIKASI}

Tingkat kepentingan departemen FO mengetahui kepuasan tamu atau peringkat hotel di situs daring adalah 5 dari 5 yang dapat ditafsirkan sebagai sangat penting. Dari wawancara yang dilakukan kepada responden, peneliti dapat menyimpulkan bahwa tingkat kepuasan tamu atau rating hotel pada situs daring harus diketahui oleh departemen Departmen kantor depan karena dapat sangat bermanfaat karena digunakan untuk meningkatkan pelayanan hotel itu sendiri. Sebagian besar responden mengatakan bahwa tingkat penting untuk mempertahankan atau meningkatkan tingkat kepuasan tamu yang diberikan oleh tamu dari ulasan daring adalah 5 dari 5 . Ini berarti bahwa sangat penting untuk mempertahankan atau meningkatkan tingkat kepuasan pelanggan.

Ulasan daring digunakan sebagai ukuran untuk kepuasan pelanggan yang dapat digunakan sebagai umpan balik. Di Ritz Carlton Jakarta, TripAdvisor menyediakan lebih banyak ulasan daring daripada Expedia dan Booking.com. Berdasarkan hasil analisis, peneliti ingin memberikan beberapa saran untuk mempertahankan dan meningkatkan kepuasan pelanggan: - Sebaiknya harus ada posisi pekerjaan yang bertanggung jawab untuk memastikan bahwa semua ulasan daring akan dijawab dan dievaluasi. - ada baiknya jika hotel mengajak lebih banyak tamu untuk memberikan komentar mereka ke TripAdvisor, atau membuat system baru dimana ketika para tamu check-out, ada notifikasi yang secara otomatis memungkinkan pelanggan untuk dapat langsung mengisi ulasan ke TripAdvisor.

\section{DAFTAR PUSTAKA}

Andrew, P. 2009, Introduction to Management in Hospitality Industry, USA.

Andrews, S. 2013, Hotel Departmen kantor depan :A Training Manual, $3^{\text {rd }}$ Edition, Tata McGraw-Hill, New Delhi.

Bagyono. 2006. Manajemen Housekeeping Hotel. Alfabeta, Bandung.

Darke, P.R. Ashworth, L., \& Main, K. 2010, ' Great Expectations and Broke Promises: Misleading Advertising, Product Failure, Expectancy Disconfirmation and Consumer Suspicion', Journal of Academy of Marketing Science, Vol. 38, No. 3, pp. 347-362.

Deng, W.J., Yeh, M.L., \& Sung, M.L. 2013, 'A Customer Satisfaction Index Model For International Tourist Hotels : Integrating Consumption Emotions Into The American Customer Satisfaction Index'. International Journal of Hospitality Management, Vol. 35, pp. 133-140. 
Dong, J., Li, H. \& Zhang, X. 2014, 'Classification of Customer Satisfaction Attributes: An Application of Daring Hotel Review Analysis', Digital Services and Information Intelligence, Vol. 445, pp. 238-250.

Enz, Cathy A. 2010, Handbook of Applied Hospitality Strategy, Sage Publications, Inc., California.

Freddy, Rangkuti. 2006. Teknik Mengukur dan Strategi Meningkatkan Kepuasan Pelanggan. Jakarta : Penerbit PT Gramedia Pustaka Utama.

Goldsmith, E.R., Litvina, W.S. \& Pana, B. 2008, 'Electronic word-of-mouth in hospitality and tourism management'. Tourism Management, Vol. 29, pp.458-468.

Grigoroudis, E. \& Siskos, Y. 2010, Customer Satisfaction Evaluation: Methods for Measuring and Implementing Service Quality, Springer Science + Business Media, LLC, New York.

Strauss, Glaser, 1967, The Discovery of Grounded Theory, United states

Gursoy D., Saayman, M. \& Sotiriadis, M. 2015, Collaboratorium in Tourism Business and Destinations : A Handbook, Emerald Group Publishing Limited, United Kingdom.

Hennig-Thurau, T., Gwinner, K.P., Walsh, G. \& Gremler, D.D. 2004, 'Electronic Word-Of-Mouth Via Consumer-Opinion Platforms: What Motivates Consumers to Articulate Themselves on the Internet?', Journal of Interactive Marketing, Vol. 18, No. 1, pp 38-53

Hill, N., Brierly, J. \& MacDougall, R. 2003, How to Measure Customer Satisfaction, $2^{\text {nd }}$ Edition, Gower Publishing Limited, England.

Hill, Nigel \& Alexander, Jim 2006, Handbook of Customer Satisfaction and Loyalty Measurement, $3^{\text {rd }}$ Edition, Gower Publishing limited, England.

Hoffman, K.D. \& Bateson, J.E.G. 2011, Service Marketing: Concepts, Strategies, $\&$ Cases, $5^{\text {th }}$ Edition, Cengage Learning, Boston. 